\title{
Características nutricionais e perdas no processo fermentativo de silagens de milho, colhidas em diferentes estádios reprodutivos com diferentes processamentos de grãos ${ }^{1}$
}

\section{Nutritional characteristics and losses on fermentation of corn silage, harvested in different reproductive stages with different grain processing}

\author{
Fabiano Marafon ${ }^{2 *}$; Mikael Neumann 3 ; Rodolfo Carletto ${ }^{4}$; Felipe de Lima Wrobel²; \\ Esther Devantier Mendes ${ }^{2}$; Cecília Aparecida Spada²; Marcos Ventura Faria ${ }^{3}$
}

\section{Resumo}

O experimento foi conduzido no Núcleo de Produção Animal (NUPRAN) da Universidade Estadual do Centro Oeste (UNICENTRO), com o objetivo de avaliar o efeito da colheita da planta de milho em diferentes estádios reprodutivos e com diferentes processamentos de grãos sobre as perdas e o valor nutritivo das silagens. Diferenças $(\mathrm{P}<0,05)$ foram evidenciadas para o quesito estádio reprodutivo, quanto aos teores de matéria seca $(26,70 \%$ contra $34,78 \%)$, matéria mineral $(4,35 \%$ contra $3,87 \%)$, fibra em detergente ácido (32,63\% contra 23,36\%) e fibra em detergente neutro $(52,06 \%$ contra $42,07 \%)$, respectivamente para os estádios grão pastoso (R3) e grão duro (R5). Elevadas perdas de matéria seca foram encontradas no estádio R3, sendo estas nas dimensões de $14,59 \%$ e $20,06 \%$, respectivamente para as silagens com e sem processador de grãos. Quanto ao parâmetro de perdas de proteína bruta, não foram evidenciadas diferenças significativas para os efeitos isolados ou associados dos estádios de colheita e processamento do grão na silagem de milho. Elevadas diferenças podem ser percebidas quanto às perdas de fibra em detergente neutro e perdas de fibra em detergente ácido das silagens, justificado pelo aumento nos teores de fibra em detergente ácido na proporção média de $22,96 \%$ nas silagens colhidas no estádio R3 e redução nos seus teores com média de 4,60\%, para o estádio R5. Não observou-se diferenças $(\mathrm{P}<0,05)$ para o tamanho de partículas quanto aos diferentes tratamentos, sendo observado significância apenas quanto a participação de grãos inteiros na massa, este variando na média de $2,59 \%$ para $10,27 \%$ da matéria seca, respectivamente para o estádio R3 e R5. De maneira geral, a ensilagem das plantas de milho em estádio reprodutivo R5 proporcionou menores perdas nutritivas da silagem no armazenamento, além de maior acúmulo de grãos na massa quando comparado ao estádio R3.

Palavras-chave: Estádios reprodutivos, perdas de nutrientes, taxa de secagem, valor relativo da silagem

\footnotetext{
1 Parte do trabalho de dissertação do primeiro autor

${ }^{2}$ Médicos Veterinários, Mestres, Programa de Pós-Graduação em Agronomia, Universidade Estadual do Centro Oeste, UNICENTRO, Campus CEDETEG, Guarapuava, PR. E-mail: fabiano_marafon@hotmail.com; felipewrobel@yahoo.com.br; estermendesmedvet@hotmail.com; spadacecilia@hotmail.com

${ }^{3}$ Eng $^{\circ}$ Agr $^{\circ}$, Prof. Dr., Programa de Pós-Graduação em Agronomia, UNICENTRO, Campus CEDETEG, Guarapuava, PR. E-mail: neumann.mikael@hotmail.com; mfaria@unicentro.br

${ }^{4}$ Eng $^{\circ}$ Agro $^{\circ}$, M.e, Programa de Pós-Graduação em Agronomia, UNICENTRO, Campus CEDETEG, Guarapuava, PR. E-mail: rodolfocarletto@hotmail.com

* Autor para correspondência
} 


\begin{abstract}
The aim of this study was evaluate the harvest of corn plant in different reproductive stages and different processing grain about losses and nutritive value of silages. Significant differences in the stage of harvest showed up in lower $(\mathrm{P}<0.05)$ for dry matter $(26.70 \%$ against $34.78 \%)$ and higher values for contents of mineral matter ( $4.35 \%$ against $3.87 \%$ ), acid detergent fiber $(32.63 \%$ vs. $23.36 \%)$ and neutral detergent fiber (52.06\% against $42.07 \%$ ) in the level of harvest dough (R3) compared to the level of hard grain (R5), respectively. High dry matter losses were found at stage R3, which are the dimensions of $14.59 \%$ and $20.06 \%$ respectively to silages with and without grain processor, significantly different $(\mathrm{P}>0.05)$ results found for the R5 stage, which had an average loss of around 5.77\%, demonstrating that silage harvested at R5 stage, allow greater dry matter recovery and hence greater savings for the farmer. Regarding the parameter of losses of crude protein, there were no significant differences for the effects of isolated or associated stages of harvesting and processing of grain in corn silage. Large differences can be perceived as the loss of neutral detergent fiber and loss of acid detergent fiber silage, justified by the increase in the levels of acid detergent fiber in the average share of $22.96 \%$ in the silage harvested at stage R3 and reduction in their concentration with an average of $4.60 \%$ for the R5 stage. No significant differences were observed $(\mathrm{P}<0.05)$ for the particle size as the different treatments, only significance being observed as the participation of whole grains in bulk, this ranging on average from $2.59 \%$ to $10.27 \%$ dry matter, respectively for stage R3 and R4-R5. In general, silage maize plant reproductive stage R5 provided smaller losses nutritious silage storage and greater accumulation of grains in bulk when compared to R3 stage.
\end{abstract}

Key words: Reproductive stages, nutrient losses, drying rate, relative value of silage

\section{Introdução}

A decisão do estádio correto em que a cultura do milho deve ser ensilada constitui o principal erro cometido por muitos produtores e técnicos. As recomendações da época ideal de colheita são variadas, sendo preconizado que a silagem deve estar com o seu teor de matéria seca entre 30 a 35\%, após a abertura do silo (NUSSIO; MANZANO, 1999). Entretanto, para que obtenhamos estes valores de matéria seca temos que levar em consideração as possíveis perdas que podem ocorrer através do processo fermentativo da silagem.

O processo de ensilagem não melhora a qualidade do alimento, visa apenas manter o valor nutricional mais próximo possível à do material antes de ser ensilado (VAN SOEST, 1994). Após a vedação do silo, inicia-se reações bioquímicas inerentes as características químicas e microbiológicas da planta ensilada, de acordo com Mühlbach (1999) essas reações são compostas por processos de origem endógena que englobam a respiração e lise celular, proteólise, degradação enzimática de oligossacarídeos à açúcares simples, ação aeróbia de fungos, leveduras e enterobactérias, ações anaeróbias controlada por lactobacilos ou por bactérias clostrídicas, reação de Maillard e a hidrólise da hemicelulose da planta, estando estes eventos fortemente ligados com a ocorrência de perdas ou com a manutenção da qualidade da silagem.

Segundo Neumann et al. (2007a), a mensuração das perdas de matéria seca e dos demais nutrientes na ensilagem é difícil e exige metodologias específicas e precisas, pois depende da coleta de amostras representativas as condições do silo. As perdas de um alimento ensilado é quantificada pelo desaparecimento, em partes, de sua constituição bromatológica, sendo a matéria seca o principal fator mensurado para estimar perdas no processo, segundo Santos et al. (2006), as perdas de energia são proporcionalmente menores que as perdas de matéria seca, justificando a utilização deste critério como parâmetro determinante de qualidade da silagem.

Neste sentido, objetivou-se avaliar o efeito da colheita da planta de milho em diferentes estádios 
reprodutivos, associado a diferentes processamentos de grãos sobre as perdas e o valor nutritivo das silagens resultantes.

\section{Material e Métodos}

O experimento foi conduzido no Núcleo de Produção Animal (NUPRAN) do setor de ciências Agrárias e Ambientais da Universidade Estadual do Centro-Oeste (UNICENTRO), no município de Guarapuava - PR, situado na zona subtropical do Paraná (MAACK, 2002), sob as coordenadas geográficas $25^{\circ} 23^{\prime} 02^{\prime \prime}$ de latitude sul e $51^{\circ} 29^{\prime} 43^{\prime \prime}$ de longitude oeste e $1.026 \mathrm{~m}$ de altitude.

O clima da região segundo a classificação de Köppen é o temperado de altitude - Cfb (Subtropical mesotérmico úmido), com verões amenos e inverno moderado, sem estação seca definida e com geadas severas. Caracterizado por temperatura média no mês mais quente inferior a $22^{\circ} \mathrm{C}$ e temperatura média no mês mais frio inferior a $18^{\circ} \mathrm{C}$. A precipitação média anual é de $1944 \mathrm{~mm}$, temperatura média mínima anual de $12,7^{\circ} \mathrm{C}$, temperatura média máxima anual de $23,5^{\circ} \mathrm{C}$ e umidade relativa do ar de $77,9 \%$ (IAPAR, 2000).

O solo da área experimental é classificado como Latossolo Bruno Típico (POTT; MÜLLER; BERTELLI, 2007), e em ocasião antecipada ao plantio apresentou as seguintes características químicas (perfil de 0 a $20 \mathrm{~cm}$ ): $\mathrm{pH} \mathrm{CaCl}_{2}$ 0,01M: 4,7; P: $1,1 \mathrm{mg} \mathrm{dm}^{-3} ; \mathrm{K}^{+}$: 0,2 $\mathrm{cmol}_{\mathrm{c}} \mathrm{dm}^{-3}$; MO: 2,62\%; $\mathrm{Al}^{3+}: 0,0 \mathrm{cmol}_{\mathrm{c}} \mathrm{dm}^{-3} ; \mathrm{H}^{+}+\mathrm{Al}^{3+}: 5,2 \mathrm{cmol}_{\mathrm{c}} \mathrm{dm}^{-3} ; \mathrm{Ca}^{2+}$ : $5,0 \mathrm{cmol}_{\mathrm{c}} \mathrm{dm}^{-3} ; \mathrm{Mg}^{2+}: 5,0 \mathrm{cmol}_{\mathrm{c}} \mathrm{dm}^{-3}$ e saturação de bases (V\%): 67,3\%.

A implantação da cultura foi efetuada uniformemente para ambos os tratamentos aos 16 dias do mês de outubro de 2010, em sistema de plantio direto, com espaçamento entre linhas de $0,8 \mathrm{~m}$, profundidade de semeadura média de 0,04 $\mathrm{m}$ e distribuição de 5 sementes por metro linear, visando obter população final de 62.500 plantas ha $^{-1}$. Por ocasião do plantio, realizou-se a adubação de base com $350 \mathrm{~kg} \mathrm{ha}^{-1}$ do fertilizante formulado 08-30-20 (N-P $\left.\mathrm{O}_{5}-\mathrm{K}_{2} \mathrm{O}\right)$. A adubação de cobertura com $120 \mathrm{~kg} \mathrm{ha}^{-1}$ de $\mathrm{N}$ na forma de uréia (46-00$00)$, foi realizada quando as plantas apresentaram quatro folhas totalmente expandidas, conforme as recomendações de adubação para cultura do milho para colheita de grãos do Manual de Adubação e de Calagem para os Estados do Rio Grande do Sul e Santa Catarina (CQFS - RS/SC, 2004).

Antecipadamente ao plantio a área foi dessecada com herbicida a base de Glifosato (produto comercial Roundup Original ${ }^{\circledR}$ : 3,0 L ha-1), no manejo da cultura até 30 dias após emergência das plantas foram aplicados herbicida a base de Atrazina (produto comercial Atrazina Atanor ${ }^{\mathbb{B}}$ : 4,0 $\mathrm{L} \mathrm{ha}^{-1}$ ), óleo mineral (produto comercial Assist ${ }^{\circledR}: 1,0 \mathrm{~L} \mathrm{ha}^{-1}$ ) e inseticida do grupo químico Piretróide (produto comercial Karate Zeon $50 \mathrm{CS}^{\circledR}: 150 \mathrm{~mL} \mathrm{ha}^{-1}$ ).

Como material experimental utilizou-se do híbrido de milho SG-6418 (híbrido duplo), de caráter granífero-silageiro, ciclo precoce, porte médio e textura de grãos duros. A gleba plantada foi dividida em 16 parcelas com 15 linhas de cultivo cada $(12 \mathrm{~m}$ x $90 \mathrm{~m})$, totalizando área total por parcela de $1.080 \mathrm{~m}^{2}$.

O objetivo do presente trabalho foi avaliar o efeito da colheita da planta de milho em dois estádios reprodutivos associados ou não ao uso de acessório quebrador de grãos na ensiladeira sobre as perdas e o valor nutritivo das silagens resultantes: T1 - Silagem de milho no estádio R3 (fase de grão pastoso) sem quebrador de grãos; T2 - Silagem de milho no estádio R3 (fase de grão pastoso) com quebrador de grãos; T3 - Silagem de milho no estádio R5 (fase de grão duro) sem quebrador de grãos e T4 - Silagem de milho no estádio R5 (fase de grão duro) com quebrador de grãos.

Para colheita da lavoura, utilizou-se da ensiladeira Pecus geração 4, de marca Nogueira, possuindo dez facas e equipada com um sistema quebra-grãos, com a possibilidade da utilização ou não deste item de série. O material colhido foi 
transportado, depositado e compactado em silos de armazenamento sob as dimensões de 1,75 m de largura, 0,8 $\mathrm{m}$ de altura e $8 \mathrm{~m}$ de comprimento, sendo completamente vedados e protegidos com lona de polietileno de três camadas $(200 \mu)$. Deste modo, em função dos tratamentos avaliados foram confeccionados 16 silos.

Durante a ensilagem, na confecção dos 16 silos, um "bag" foi locado no perfil de cada silo com peso conhecido, sendo estes considerados como unidades experimentais. A designação de "bag" refere-se a um saco de náilon maleável 100\% poliamina, com poros de 85 micrômetros, dimensões de $12 \mathrm{~cm}$ de diâmetro e $50 \mathrm{~cm}$ de comprimento, com capacidade média de $2 \mathrm{~kg}$, com nível de compactação prévio aproximado de $350 \mathrm{~kg} \mathrm{~m}^{3-1}$ de matéria verde (material original) (NEUMANN, 2006). Os "bags" foram dispostos na porção intermediária do perfil dos silos.

Cada "bag" foi identificado, pesado individualmente vazio e novamente pesado após seu enchimento com o material original. A compactação final da massa contida nos "bags" foi efetuada pelo trator no silo, buscando a mesma compactação entre material original do "bag" e do silo.

No momento da inserção dos "bags" em cada um dos silos, paralelamente, foram coletados amostras semelhantes (homogêneas e representativas) dos materiais originais para congelamento. Com a abertura dos silos que ocorreu em média 60 dias após a ensilagem, resgatou-se as amostras de silagens contidas em cada "bag", onde uma parte, na forma "in natura", foi utilizada para determinação de $\mathrm{pH}$, enquanto a outra parte foi pesada e levada para estufa de circulação forçada de ar a $55^{\circ} \mathrm{C}$ por 72 horas para determinação do teor de matéria seca (MS) (SILVA; QUEIROZ, 2009).

Após abertura dos silos, com a localização dos "bags", estes foram imediatamente pesados, e coletado amostras para as avaliações laboratoriais, possibilitando assim as avaliações, do mesmo material em suas diferentes condições (forragem e silagem). As perdas de matéria seca, de proteína bruta, fibra em detergente ácido e fibra em detergente neutro, foram expressas por diferença de gradientes de concentração entre material original e material desensilado, associado ao peso dos "bags" na ensilagem e desensilagem, seguindo a seguinte equação: Perda de nutriente $=[(1-(g$ nutriente na silagem $\div$ g nutriente na matéria original)) $\mathrm{x} 100]$ conforme metodologia descrita por Neumann (2006).

Após abertura dos silos, também foram realizadas mensurações diárias de temperatura ambiente e dos perfis dos silos com o auxílio de um termômetro, avaliações semanais do potencial hidrogeniônico $(\mathrm{pH})$ e avaliações de massa específica dos silos, com o auxílio de um anel, possuindo medidas conhecidas, sendo introduzido no perfil dos silos.

As amostras pré secas de material original e de silagem resgatadas dos bags foram moídas a $1 \mathrm{~mm}$ em moinho tipo "Willey", onde sequencialmente determinou-se a matéria seca total em estufa a $105^{\circ} \mathrm{C}$ por 16 horas (SILVA; QUEIROZ, 2009), proteína bruta $(\mathrm{PB})$ pelo método micro Kjeldahl, matéria mineral $(\mathrm{MM})$ por incineração a $550^{\circ} \mathrm{C}(4$ horas) e matéria orgânica (MO) por diferença (\% $\mathrm{MO}=100-\mathrm{MM})$, conforme AOAC (1995). Foram determinados os teores de fibra em detergente neutro (FDN), conforme Van Soest, Roberttson e Lewis (1991), utilizando-se $\alpha$ amilase termo-estável (Termamyl 120L, Novozymes Latin América Ltda.), fibra em detergente ácido (FDA) segundo Goering e Van Soest (1970) e os teores de Hemicelulose por diferença (Hemicelulose $=$ FDN - FDA) seguindo metodologia proposta por Silva e Queiroz (2009).

Os valores para consumo de matéria seca em relação ao peso vivo (CMSP) foram obtidos através da fórmula: $\mathrm{CMSP}=120 \div \mathrm{FDN}$, enquanto que os teores de nutrientes digestíveis totais (NDT, \%) foram obtidos via equação: NDT, $\%=87,84-(0,70$ x FDA) conforme Bolsen (1996). O valor relativo da silagem (VRS) foi expresso pela associação entre potencial de consumo de matéria seca e 
digestibilidade estimada da matéria seca (DMS): $\mathrm{VRS}=[(\mathrm{DMS} \times \mathrm{CMSP}) \div 1,29]$.

A estimativa do tamanho de partículas foi embasada na metodologia da separação de partículas (base do peso in natura) por peneiras, utilizando o equipamento "Penn State Particle Size Separator" (SPPS), definindo a proporção de material retido com diâmetro superior a 1,905 $\mathrm{cm}$, intermediário a 1,905 e $0,787 \mathrm{~cm}$ e inferior a 0,787 cm (HEINRICHS; KONONOFF, 2002). A determinação da porcentagem de grãos inteiros presentes nas diferentes silagens foi realizada mediante separação dos mesmos das partículas das silagens retidas no extrato intermediário do separador de partículas, realizando-se sequencialmente a pesagem, sendo posteriormente levado para estufa de ar forçado a $55^{\circ} \mathrm{C}$ por 72 horas para determinação de matéria seca.

O delineamento experimental foi o inteiramente casualizado, composto por quatro tratamentos com quatro repetições, em um esquema fatorial 2 x 2 sendo dois estádios de colheita (R3 e R5) e dois processamento de grãos (com ou sem). Os dados foram submetidos à análise de variância com comparação de médias a 5\% de significância, por intermédio do programa estatístico SAS (1993).

\section{Resultados e Discussão}

Podemos Averiguar, na Tabela 1, a existência de diferenças significativas $(\mathrm{P}<0,05)$ para o quesito de avaliação estádio de colheita, entre as variáveis teores de matéria seca $(26,70 \%$ contra $34,78 \%)$, fibra em detergente ácido $(31,63 \%$ contra $23,36 \%)$, fibra em detergente neutro (52,06\% contra $41,07 \%)$ e matéria mineral $(4,35 \%$ contra $3,87 \%)$, apresentado respectivamente aos estádios reprodutivos de $\mathrm{R} 3$ e R5. Já para os teores de proteína bruta, não houve interação significativa $(\mathrm{P}>0,05)$, individual ou combinada entre estádio de colheita e processamento do grão, apresentando média geral de 6,25\%.

No entanto, observa-se que não houve interação significativa $(\mathrm{P}>0,05)$ entre estádio de colheita e processamento de grãos para os valores médios de matéria seca (MS), de proteína bruta (PB), de fibra em detergente ácido (FDA), de fibra em detergente neutro (FDN) e de matéria mineral (MM) das silagens resultantes.

As silagens resultantes da colheita das plantas de milho em estádio R5, apresentaram menores teores de fibra em detergente ácido, fibra em detergente neutro e cinzas, sugerindo a ocorrência do efeito de diluição destas frações com a transformação dos açúcares simples em amido no componente grão com o avanço do ciclo reprodutivo. Apesar da perca de qualidade da fração fibrosa das silagens colhidas em estádios avançados de maturação, o aumento da participação de grãos no total da planta melhora os níveis energéticos e a qualidade da silagem, em maiores proporções que as percas de qualidade da porção fibrosa da silagem (OLIVEIRA, 2010).

De acordo com Johnson et al. (2002), o estádio de colheita da planta de milho afeta, de forma direta, a produção de matéria seca por unidade de área. Pode-se evidenciar alteração sob ordem quantitativa, pelo acúmulo de matéria seca oriundo do avanço do ciclo da cultura, quanto qualitativa pela dinâmica acumulativa de nutrientes apresentada pela planta com o decorrer dos dias, causando alterações relacionadas a fração fibrosa e a densidade energética da silagem (OLIVEIRA et al., 2011).

Quanto aos teores de proteína bruta, Filya (2004) encontrou valores próximos ao presente estudo, respectivamente para forragem e silagem de milho colhidas nos estádios de início de formação de grãos $(7,7 \%$ contra $8,0 \%), 1 / 3$ da linha do leite $(6,9 \%$ contra $7,2 \%), 2 / 3$ da linha do leite $(6,2 \%$ contra $6,5 \%)$ e ponto negro no grão $(5,6 \%$ contra $5,8 \%$ ), podendo ser observado um efeito de diluição da PB com o decorrer do ciclo da planta, fato este justificado pelo acúmulo de grãos na massa total.

Oliveira (2010) trabalhando com silagens de milho colhidas em dois estádios reprodutivos, 
possuindo teores de matéria seca de $25,6 \%$ e $32,6 \%$ encontrou diferenças significativas $(\mathrm{P}>0,05)$ para as mensurações de proteína bruta $(8,0 \%$ contra $7,4 \%)$ e digestibilidade in vitro da matéria seca das plantas $(62,6 \%$ contra $64,5 \%)$, respectivamente.

Tabela 1. Teores de matéria seca, proteína bruta, fibra em detergente ácido, fibra em detergente neutro e matéria mineral das silagens, conforme estádio de reprodutivo e processamento dos grãos com base na matéria seca.

\begin{tabular}{|c|c|c|c|}
\hline Processamento de grãos & \multicolumn{2}{|c|}{ Estádio Reprodutivo } & \multirow[t]{2}{*}{ Média } \\
\hline & Grão Pastoso, R3 & Grão Duro, R5 & \\
\hline & \multicolumn{2}{|c|}{ Matéria seca, $\%$} & \multirow[b]{2}{*}{$30,31 \mathrm{a}$} \\
\hline Sem & 26,25 & 34,37 & \\
\hline Com & 27,16 & 35,19 & $31,17 \mathrm{a}$ \\
\hline Média & $26,70 \mathrm{~B}$ & $34,78 \mathrm{~A}$ & \\
\hline \multicolumn{4}{|c|}{ Proteína bruta, $\%$ na MS } \\
\hline Sem & 6,32 & 6,15 & $6,23 \mathrm{a}$ \\
\hline Com & 6,43 & 6,11 & $6,27 \mathrm{a}$ \\
\hline Média & $6,37 \mathrm{~A}$ & $6,13 \mathrm{~A}$ & \\
\hline \multicolumn{4}{|c|}{ Fibra em detergente ácido, $\%$ na MS } \\
\hline Sem & 29,83 & 23,15 & $26,49 a$ \\
\hline Com & 33,44 & 23,58 & $28,51 \mathrm{a}$ \\
\hline Média & $31,63 \mathrm{~A}$ & $23,36 \mathrm{~B}$ & \\
\hline \multicolumn{4}{|c|}{ Fibra em detergente neutro, $\%$ na MS } \\
\hline Sem & 49,67 & 41,48 & $45,57 \mathrm{a}$ \\
\hline Com & 54,45 & 40,66 & $47,55 \mathrm{a}$ \\
\hline Média & $52,06 \mathrm{~A}$ & $41,07 \mathrm{~B}$ & \\
\hline \multicolumn{4}{|c|}{ Matéria mineral, \% na MS } \\
\hline Sem & 4,42 & 3,92 & $4,17 \mathrm{a}$ \\
\hline Com & 4,28 & 3,82 & $4,05 \mathrm{a}$ \\
\hline Média & $4,35 \mathrm{~A}$ & $3,87 \mathrm{~B}$ & \\
\hline
\end{tabular}

Médias seguidas de letras maiúsculas diferentes na linha ou seguidas de letras minúsculas diferentes na coluna, diferem entre si $(\mathrm{P}<0,05)$ pelo Teste $\mathrm{F}$ a $5 \%$.

Fonte: Elaboração dos autores.

Corroborando com os resultados do presente trabalho, Senger et al. (2005) evidenciaram redução nos teores de fibra em detergente neutro da silagem quando comparadas com o material sem sofrer fermentação (forragem), das amostras colhidas entre 26 e $28 \%$ de MS, justificando este fato com a ocorrência de degradação da hemicelulose em meios ácidos, entretanto os autores encontraram aumento nos teores de fibra em detergente neutro com as plantas sendo colhidas com $20 \%$ de MS, podendo ser justificado pela grande quantidade de efluente produzida por este material.

Souza Filho et al. (2011) relataram que a porção vegetativa da planta de milho perde sua qualidade com o avanço do ciclo da cultura, no entanto, existe grande diluição dessa perda de qualidade pelo acúmulo de grãos, que de forma geral mantém a qualidade da forragem. Em complementação os autores observaram diluição nos teores de fibra em detergente neutro em plantas com avançado estádio de maturação, contudo, está porção apresentou queda na degradabilidade da matéria seca, sugerindo 
alterações nas proporções de seus constituintes hemicelulose, celulose e lignina.

Existe especulações de que a porção vegetativa da planta de milho perde sua qualidade com o avanço do ciclo da cultura, no entanto, existe grande diluição dessa perda de qualidade pelo acúmulo de grãos, que de forma geral mantém a qualidade da forragem, pois dilui sua fração fibrosa (SOUZA FILHO et al., 2011).

Nesse sentido, materiais que apresentam menor fibra em detergente neutro como podem observar na silagem colhida em estádio R5 (Tabela 1), apresentam melhor consumo e aproveitamento pela parte animal, melhorando seu desempenho produtivo. Em concordância com a afirmação anterior, podemos citar o trabalho de Oba e Allen (2000) onde os autores sugerem redução no enchimento físico do rúmen quando os animais são alimentados com volumosos possuindo maior taxa de degradação da fibra em detergente neutro, demonstrando expressivo aumento na ingestão de matéria seca $\left(24,3\right.$ contra $22,2 \mathrm{~kg} \cdot \mathrm{dia}^{-1}$ de MS) e produção de leite $\left(35,2\right.$ contra $\left.32,0 \mathrm{~kg} \mathrm{dia}^{-1}\right)$, quando os animais foram alimentados com dietas de baixa e alta proporção de fibra em detergente neutro, respectivamente.

A fração fibrosa do material ensilado pode ser modificada, principalmente pelo desenvolvimento de microrganismos que consomem em grande quantidade os carboidratos solúveis presente na planta, de parte da celulose e da degradação variável da hemicelulose em meios ácidos, causando alterações da porção fibrosa da silagem (VAN SOEST, 1994).

Não houve interação significativa $(\mathrm{P}>0,05)$ entre estádio reprodutivo e processamento de grãos para variáveis apresentadas na Tabela 2. As silagens colhidas no estádio reprodutivo R5, independente do processamento de grãos, apresentaram melhores consumo de matéria seca em relação ao peso vivo, melhores níveis de nutrientes digestíveis totais e melhores índices de valor relativo do alimento.

Tabela 2. Médias para consumo de matéria seca estimado em porcentagem do peso vivo, nutrientes digestíveis totais e valor relativo das silagens, conforme estádio de reprodutivo e processamento dos grãos.

\begin{tabular}{cccc}
\hline & \multicolumn{2}{c}{ Estádio Reprodutivo } & Média \\
\hline & \multicolumn{2}{c}{ Grão Pastoso, R3 } & \\
\cline { 2 - 3 } Processamento de grãos & \multicolumn{1}{c}{ Consumo de matéria seca, \% do peso vivo } \\
Com & 2,43 & 2,90 & $2,66 \mathrm{a}$ \\
Média & 2,21 & 2,99 & $2,60 \mathrm{a}$ \\
Sem & $2,32 \mathrm{~B}$ & $2,94 \mathrm{~A}$ & \\
Com & Nutrientes digestíveis totais, \% na MS & $69,29 \mathrm{a}$ \\
Média & 66,96 & 71,63 & $67,88 \mathrm{a}$ \\
& 64,43 & 71,33 & \\
Sem & $65,69 \mathrm{~B}$ & $71,48 \mathrm{~A}$ \\
Com & Valor relativo da silagem, Índice & \\
Média & 126,81 & 161,19 & $144,00 \mathrm{a}$ \\
\hline
\end{tabular}

Médias seguidas de letras maiúsculas diferentes na linha ou seguidas de letras minúsculas diferentes na coluna diferem entre si $(\mathrm{P}<0,05)$ pelo Teste $\mathrm{F}$ a $5 \%$.

Fonte: Elaboração dos autores. 
Os critérios de avaliação de consumo de matéria seca e nutrientes digestíveis totais apresentaram melhores resultados $(\mathrm{P}>0,05)$ para as silagens colhidas em estádio fenológico R5, isso se deve ao maior acúmulo de grãos na biomassa total com o decorrer do ciclo da planta, sendo estes ricos em amido e possuindo baixas taxas de fibras em sua constituição, culminando na diluição dos teores da porção fibrosa da planta de milho, refletindo diretamente na capacidade de ingestão pelo animal.

Tais resultados vão de encontro ao trabalho realizado por Cabral et al. (2002), que trabalhando com silagem de milho contendo diferentes proporções de grãos na massa, $0 \%, 15 \%, 30 \%, 45 \%$ e $60 \%$, observaram valores de nutrientes digestíveis totais, na ordem de $56,08 \%, 63,54 \%, 69,25 \%$, $75,42 \%$ e $81,40 \%$, respectivamente.

Os dados descrito por Cabral et al. (2002) e os dados obtidos no presente trabalho, reforçam a teoria de diluição da fração fibrosa da planta com a maior participação de grãos na sua constituição, sendo demonstrado também no valor relativo do alimento, índice este que leva em consideração a estimativa do valor nutricional da forragem, onde o mesmo combina o consumo estimado através da fibra em detergente neutro concomitantemente à digestibilidade do alimento obtida por meio da fibra em detergente ácido, sendo que este valor deve ser usado para comparação somente entre plantas forrageiras (RASBY, 2011).

A Tabela 3 mostra as perdas oriundas do processo fermentativo da silagem, conforme os diferentes tratamentos. Houve interação significativa $(\mathrm{P}<0,05)$ entre estádio reprodutivo e processamento de grãos para as perdas de matéria seca, enquanto que para demais variáveis a interação não foi significativa.

O fenômeno denominado perda de matéria seca através da fermentação anaeróbia é fato comum quando se fala em ensilagem, no presente trabalho, maiores perdas de matéria seca foram observadas no estádio R3, sendo estas nas dimensões de 14,59\% e $20,06 \%$, respectivamente para as silagens com e sem processador de grãos. As perdas observadas no estádio R3 diferem estatisticamente $(\mathrm{P}>0,05)$ dos resultados encontrados para o estádio $\mathrm{R} 5$, sendo a média das perdas para este na ordem de 5,77\%, demonstrando que silagens colhidas em estádio $\mathrm{R} 5$, possibilitam menores perdas pelo processo fermentativo, consequentemente, maior economia para o produtor rural.

Quanto ao parâmetro de perdas de proteína bruta, não foram evidenciadas diferenças significativas $(\mathrm{P}<0,05)$ para os efeitos isolados ou associados dos estádios de colheita e processamento do grão na silagem de milho.

Pode-se considerar as perdas de matéria seca como de elevada monta, principalmente no estádio R3, sugerindo variações no processo bioquímico da silagem (TOSI; JOBIM, 2001) os quais podem acontecer em situações de umidade do material original (forragem) superior a 70\% no momento da ensilagem. De acordo com Tabacco et al. (2011), as perdas de matéria seca podem chegar a proporções de $70 \%$ do total ensilado, ocorrendo principalmente nas periferias, próximos as paredes dos silos, sendo relatadas depleção na digestibilidade dos carboidratos e menores frações de ácidos orgânicos.

$\mathrm{Hu}$ et al. (2009), realizando colheita da planta de milho em dois estádios reprodutivos, sendo o primeiro considerado como normal pelos autores, apresentando teor de matéria seca de 32,7\% e o segundo denominado como moderadamente alto apresentando teor de matéria seca de 39,1\%, procedeu-se abertura do silo 240 dias após vedação e o material apresentou uma taxa de recuperação de matéria seca de $99,0 \%$ e $98,6 \%$, respectivamente para o material normal e moderadamente alto. Dados estes que destoam do presente trabalho, o qual nos demonstrou recuperação de matéria seca na ordem de $76,46 \%$ e $92,04 \%$ para os estádios de R3 e R5 respectivamente.

Trabalhando com silagem de milho colhida com 33,71\% de MS, Zanette (2010) encontrou perdas de matéria seca de $14,66 \%, 16,99 \%$ e 
$11,87 \%$ para os tratamentos denominados como silagem convencional, aditivada com açúcar e silagem com inoculante bacteriano. A autora complementa que a utilização de inoculantes durante o processo de ensilagem pode refletir em aumento na digestibilidade da mesma forma que aumenta a recuperação de matéria seca do material ensilado, no entanto, fatores como massa específica e potencial hidrogeniônico podem ter efeitos direto na qualidade da silagem.

Tabela 3. Perdas médias de matéria seca, de proteína bruta, de fibra em detergente ácido e de fibra em detergente neutro das silagens, conforme estádio de reprodutivo e processamento dos grãos.

\begin{tabular}{|c|c|c|c|}
\hline Processamento de grãos & \multicolumn{2}{|c|}{ Estádio Reprodutivo } & \multirow[t]{2}{*}{ Média } \\
\hline & Grão Pastoso, R3 & Grão Duro, R5 & \\
\hline & \multicolumn{2}{|c|}{ Perdas de matéria seca, $\%$} & \multirow{4}{*}{$\begin{array}{l}13,04 \\
10,32\end{array}$} \\
\hline Sem & $20,60 \mathrm{aA}$ & $5,49 \mathrm{aB}$ & \\
\hline Com & $14,59 \mathrm{bA}$ & $6,05 \mathrm{aB}$ & \\
\hline Média & 17,59 & 5,77 & \\
\hline \multicolumn{4}{|c|}{ Perdas de proteína bruta, $\%$} \\
\hline Sem & 9,11 & 7,32 & $8,21 \mathrm{a}$ \\
\hline Com & 6,00 & 7,79 & $6,89 \mathrm{a}$ \\
\hline Média & $7,55 \mathrm{~A}$ & $7,55 \mathrm{~A}$ & \\
\hline \multicolumn{4}{|c|}{ Perdas de fibra em detergente ácido, \% } \\
\hline Sem & $-16,03$ & 3,37 & $-6,33 a$ \\
\hline Com & $-29,89$ & 5,83 & $-12,03 \mathrm{a}$ \\
\hline Média & $-22,96 \mathrm{~B}$ & $4,60 \mathrm{~A}$ & \\
\hline \multicolumn{4}{|c|}{ Perdas de fibra em detergente neutro, $\%$} \\
\hline Sem & $-4,87$ & 4,00 & $0,43 \mathrm{a}$ \\
\hline Com & $-20,25$ & 10,23 & $-5,01 \mathrm{a}$ \\
\hline Média & $-12,56 \mathrm{~B}$ & $7,12 \mathrm{~A}$ & \\
\hline
\end{tabular}

Médias seguidas de letras maiúsculas diferentes na linha ou seguidas de letras minúsculas diferentes na coluna diferem entre si $(\mathrm{P}<0,05)$ pelo Teste $\mathrm{F}$ a $5 \%$.

Na interação entre estádio reprodutivo e processamento de grãos, letras minúsculas diferentes na coluna compara o efeito do estádio reprodutivo dentro de cada processamento, enquanto que letras maiúsculas diferentes na linha compara o efeito do processamento dentro de cada estádio reprodutivo, pelo Teste $\mathrm{F}$ a $5 \%$.

Fonte: Elaboração dos autores.

Oliveira (2010) evidenciou perdas de matéria seca na ordem de 9,8 e 2,6\% e de proteína bruta de 8,9 contra $0,7 \%$ em silagens colhidas em dois estádios reprodutivos, contendo $25,6 \%$ e $32,6 \%$ de MS, sendo significante os dados em relação a perdas de proteína bruta, fato este não observado no presente trabalho, o qual mostrou perdas de proteína bruta em maiores montas na ordem de $9,11 \%$ contra $6,01 \%$ para estádio R3 e R5, respectivamente.

Contudo, elevadas diferenças podem ser percebidas quanto às perdas de fibra em detergente neutro e perdas de fibra em detergente ácido das silagens, justificado pelo aumento nos teores de fibra em detergente ácido na proporção média de $22,96 \%$ nas silagens colhidas no estádio R3 e redução nos seus teores com média de $4,60 \%$, para o estádio R5. Comportamento semelhante ao descrito anteriormente é evidenciado para o parâmetro perdas de fibra em detergente neutro, o qual obteve resultado médio de $-12,56 \%$ para o estádio R3 contra $7,12 \%$ para o estádio R5. 
O decréscimo nos conteúdos de carboidratos solúveis e de hemicelulose, sendo mensurada pela fibra em detergente neutro, pode causar efeito de diluição e, consequentemente, elevação nos teores de fibra em detergente neutro e de fibra em detergente ácido (REIS; JOBIM, 2000), uma vez que os dados são expressos em porcentagem da matéria seca (NEUMANN et al., 2007a), isso explica os resultados obtidos nas avaliações de perdas do presente trabalho.

Efeito contrário ao obtido no presente estudo foi evidenciado por $\mathrm{Hu}$ et al. (2009), os quais evidenciaram incremento nos teores de fibra em detergente neutro $(39,6 \%$ contra $42,3 \%)$ e de fibra em detergente ácido (24,5\% contra 25,5\%) para silagem de milho colhidas em dois estádios reprodutivos, com teores de matéria seca de 32,7\% e $39,1 \%$ respectivamente, justificando que os teores dos elementos fibrosos podem aumentar quando a concentração de carboidratos solúveis decresce na planta.

Em complementação, Stokes e Chen (1994) concluíram que as atuações das enzimas e dos ácidos orgânicos produzidos pela fermentação possuíram atuação continua sobre os constituintes da parede celular, observando redução nos valores de celulose e hemicelulose 28 dias após a fermentação da silagem, não apresentando acúmulo de carboidratos solúveis. No entanto os autores evidenciaram redução em maior escala, nos componentes estruturais da silagem comparada com a forragem durante os quatro dias iniciais de fermentação.

No presente trabalho podemos justificar a elevada perda de matéria seca no estádio R3 pela alta umidade apresentada pela planta no momento da ensilagem, sendo observada produção de efluentes nos silos de armazenamento das silagens. Na Tabela 4 encontram-se os resultados de temperatura da silagem, gradiente de temperatura entre silagem e temperatura ambiente, massa específica do silo e índice de $\mathrm{pH}$ das silagens colhidas em diferentes estádios reprodutivos possuindo diferentes processamentos de grãos. Não houve interação significativa $(\mathrm{P}>0,05)$ entre estádio reprodutivo $\mathrm{e}$ processamento de grãos para variáveis supracitadas.

Silagens colhidas em estádio reprodutivo R5, independente do processamento de grãos, com maiores teores de matéria seca, apresentaram temperaturas maiores que silagens colhidas no estádio R3, fato este que mostrado também entre o gradiente de temperatura da silagem com a temperatura ambiente, o qual determinou diferenças estatísticas $(\mathrm{P}>0,05)$ entre as silagens colhidas em diferentes estádios reprodutivos, sendo este na ordem de $17,08^{\circ} \mathrm{C}$ contra $6,14^{\circ} \mathrm{C}$ para silagens em R5 e R3 respectivamente. Jobim et al. (2007) sugerem que as silagens não deveriam ultrapassar a temperatura ambiente em mais que $2^{\circ} \mathrm{C}$, sendo considerado como ocasião que ocorre a quebra da estabilidade aeróbia das silagens, iniciando sua degradação em temperaturas superiores.

No presente trabalho pode-se explicar as maiores temperaturas da silagem em estádio R5 pela maior participação da fração energética, apresentando mais substrato para desenvolvimento de microrganismos e também pela menor compactação apresentado por este material $(611,87$ $\mathrm{kg} \mathrm{m}^{3-1}$ contra $772,25 \mathrm{~kg} \mathrm{~m}^{3-1}$, para silagens em estádio R5 e R3, respectivamente), apresentando reflexo direto nos índices de $\mathrm{pH}$ apresentados pelas silagens, os quais tiveram diferenças significativas $(\mathrm{P}<0,05)$, sendo o índice de 3,81 para silagem em estádio R5 e 3,61 para silagem em estádio R3. Índices estes considerados satisfatórios pois, de acordo com (NEUMANN et al., 2011), silagens de milho devem apresentar índices de $\mathrm{pH}$ abaixo de 4,0 após a ocorrência de fermentação a nível de silo. 
Tabela 4. Médias para temperatura das silagens, gradiente de temperatura entre silagem e ambiente, massa específica e pH oriundos das silagens, conforme estádio de reprodutivo e processamento dos grãos.

\begin{tabular}{|c|c|c|c|}
\hline Processamento de grãos & \multicolumn{2}{|c|}{ Estádio reprodutivo } & \multirow[t]{2}{*}{ Média } \\
\hline & Grão Pastoso, R3 & Grão Duro, R5 & \\
\hline & \multicolumn{2}{|c|}{ Temperatura da silagem, ${ }^{\circ} \mathrm{C}$} & \multirow{4}{*}{$\begin{array}{l}30,70 a \\
32,53 a\end{array}$} \\
\hline Sem & 25,17 & 36,22 & \\
\hline Com & 27,12 & 37,95 & \\
\hline Média & $26,14 \mathrm{~B}$ & $37,08 \mathrm{~A}$ & \\
\hline \multicolumn{4}{|c|}{ Gradiente entre silagem e ambiente, ${ }^{\circ} \mathrm{C}$} \\
\hline Sem & 5,17 & 16,22 & $10,70 \mathrm{a}$ \\
\hline Com & 7,12 & 17,95 & $12,53 a$ \\
\hline Média & $6,14 \mathrm{~B}$ & $17,08 \mathrm{~A}$ & \\
\hline \multicolumn{4}{|c|}{ Massa específica, $\mathrm{kg} / \mathrm{m}^{3}$} \\
\hline Sem & 760,50 & 595,00 & $677,75 \mathrm{a}$ \\
\hline Com & 784,00 & 628,75 & $706,37 \mathrm{a}$ \\
\hline Média & $772,25 \mathrm{~A}$ & $611,87 \mathrm{~B}$ & \\
\hline \multicolumn{4}{|c|}{$\mathrm{pH}$, Índice } \\
\hline Sem & 3,63 & 3,80 & $3,71 \mathrm{a}$ \\
\hline Com & 3,59 & 3,82 & $3,70 \mathrm{a}$ \\
\hline Média & $3,61 \mathrm{~B}$ & $3,81 \mathrm{~A}$ & \\
\hline
\end{tabular}

Médias seguidas de letras maiúsculas diferentes na linha ou seguidas de letras minúsculas diferentes na coluna diferem entre si $(\mathrm{P}<0,05)$ pelo Teste $\mathrm{F}$ a $5 \%$.

Na interação entre estádio reprodutivo e processamento de grãos, letras minúsculas diferentes na coluna compara o efeito do estádio reprodutivo dentro de cada processamento, enquanto que letras maiúsculas diferentes na linha compara o efeito do processamento dentro de cada estádio reprodutivo, pelo Teste F a $5 \%$.

Fonte: Elaboração dos autores.

Na Tabela 5 estão apresentados os dados referentes ao tamanho de partículas e porcentagem de grãos inteiros presentes nas silagens resultantes dos diferentes tratamentos.

Pode-se observar efeito individual e associado entre estádios de colheita e processador quanto ao número de grãos inteiros contidos na massa ensilada. Foi observada diferença $(\mathrm{P}<0,05)$ entre a utilização ou não do acessório quebrador de grãos, com valores de 7,22\% de grãos inteiros na silagem sem o quebrador e de 5,63\% na silagem colhida com o acessório, confirmando uma atuação deste acessório na ordem de $22,00 \%$ no total de grãos inteiros presente na silagem.

Já para o estádio R3 este efeito não pode ser observado, apresentando valor médio de $2,59 \%$ de grãos inteiros na massa ensilada, sendo justificado pela grande diferença produtiva de grãos encontrada entre os diferentes estádios reprodutivos em que a planta de milho foi colhida. Justifica-se o fato de não apresentar efeito sobre os grãos no estádio R3, pelo episódio de que a planta de milho inicia o enchimento de grãos primeiramente com açucares simples, que subsequentemente, serão transformados em amido (RITCHIE; HANWAY; BENSON, 2003). 
Tabela 5. Distribuição percentual de partículas por peneiras e porcentagem de grãos inteiros (base no peso in natura), presentes na massa das silagens, conforme estádio de reprodutivo e processamento dos grãos.

\begin{tabular}{|c|c|c|c|}
\hline \multirow[t]{2}{*}{ Processamento de grãos } & \multicolumn{2}{|c|}{ Estádio Reprodutivo } & \multirow[t]{2}{*}{ Média } \\
\hline & Grão Pastoso, R3 & Grão Duro, R5 & \\
\hline & \multicolumn{2}{|c|}{ Peneira $>1,9 \mathrm{~cm}, \%$} & \\
\hline Sem & 12,00 & 12,00 & $12,00 \mathrm{a}$ \\
\hline Com & 12,17 & 12,35 & $12,26 \mathrm{a}$ \\
\hline Média & $12,08 \mathrm{~A}$ & $12,17 \mathrm{~A}$ & \\
\hline \multicolumn{4}{|c|}{ Peneira entre 0,7 a $1,9 \mathrm{~cm}, \%$} \\
\hline Sem & 50,00 & 46,62 & $48,31 \mathrm{a}$ \\
\hline Com & 46,30 & 43,45 & $44,87 \mathrm{~b}$ \\
\hline Média & $48,15 \mathrm{~A}$ & $45,03 \mathrm{~B}$ & \\
\hline \multicolumn{4}{|c|}{ Peneira $<0,7 \mathrm{~cm}, \%$} \\
\hline Sem & 38,02 & 41,37 & $39,69 \mathrm{a}$ \\
\hline Com & 41,52 & 44,25 & $42,88 b$ \\
\hline Média & $39,77 \mathrm{~B}$ & $42,81 \mathrm{~A}$ & \\
\hline \multicolumn{4}{|c|}{ Grãos inteiros na silagem, \% na MS } \\
\hline Sem & $2,60 \mathrm{aB}$ & $11,85 \mathrm{aA}$ & 7,22 \\
\hline Com & $2,57 \mathrm{aB}$ & $8,70 \mathrm{bA}$ & 5,63 \\
\hline Média & 2,59 & 10,27 & \\
\hline
\end{tabular}

Médias seguidas de letras maiúsculas diferentes na linha ou seguidas de letras minúsculas diferentes na coluna diferem entre si $(\mathrm{P}<0,05)$ pelo Teste $\mathrm{F}$ a $5 \%$.

Na interação entre estádio reprodutivo e processamento de grãos, letras minúsculas diferentes na coluna compara o efeito do estádio reprodutivo dentro de cada processamento, enquanto que letras maiúsculas diferentes na linha compara o efeito do processamento dentro de cada estádio reprodutivo, pelo Teste $\mathrm{F}$ a 5\%.

Fonte: Elaboração dos autores.

O tamanho médio das partículas na confecção de silagem de milho dá-se pela proporção ideal de partículas retidas em diferentes peneiras, que de acordo com Heinrichs e Kononoff (2002), seria uma distribuição de 3 a $8 \%$ das partículas retidas na peneira superior, de 30 a $50 \%$ na peneira de 0,7 a $1,9 \mathrm{~cm}$ e de 45 a $65 \%$ de partículas menores que $0,7 \mathrm{~cm}$.

Com o avanço no ciclo da planta ocorrem alterações na constituição da porção fibrosa, fato que aumenta a resistência ao processo de picagem. No presente estudo verificou-se que plantas em estádio reprodutivo de R5 apresentaram melhores tamanhos de partículas, quando comparado com o estádio R3, demonstrando desta forma, que o tamanho de partícula está diretamente relacionado ao manejo e regulagens do maquinário de colheita.
De acordo com Kononoff, Heinrich e Lehman (2003) e Neumann et al. (2007b), a distribuição apropriada do tamanho de partículas do volumoso é importante para a formulação de dietas, estabelecendo uma relação direta com o grau de seletividade da mesma, tempo de ruminação, estabilidade do $\mathrm{pH}$ rumenal, taxa de passagem, grau de degradação microbiana rumenal e, consequentemente, a constância na produção animal, quer seja esta carne ou leite.

Relatos (RESTLE et al., 2002; RABELO et al., 2012) indicam que menores tamanhos de partículas podem favorecer a fermentação, minimizando a produção de ácido butírico, facilitando a compactação, promovendo maior superfície de contato entre substrato e microorganismos e disponibilizando mais conteúdo celular para as reações bioquímicas dentro do silo. 
Oliveira (2010) trabalhando com silagens de milho colhidas em dois estádios reprodutivos sob teores de matéria seca de $25,6 \%$ e $32,6 \%$ encontrou diferenças significativas quanto a porcentagem do tamanhos de partículas sendo, respectivamente de $13,7 \%$ contra $22,4 \%$ (peneira $>1,9 \mathrm{~cm}$ ), de $57,1 \%$ contra $51,4 \%$ (peneira entre 0,7 a $1,9 \mathrm{~cm}$ ) e de $29,2 \%$ contra $26,2 \%$ (peneira $<0,7 \mathrm{~cm}$ ), justificando as alterações pela maior resistência (maior quantidade de fibra) ao processamento apresentado pela planta colhida com $32,6 \%$ de MS.

\section{Conclusão}

A ensilagem das plantas de milho em estádio reprodutivo R5 proporciona menores perdas nutritivas durante o armazenamento da silagem, além de aumentar a densidade energética da silagem resultante. $\mathrm{O}$ acessório quebrador de grãos possibilita maiores danificações no pericarpo, rompendo a barreira física entre o meio externo e o endosperma dos grãos.

\section{Referências}

ASSOCIATION OF OFFICIAL ANALYTICAL CHEMISTS - AOAC. Official methods of analysis. 16. ed. Washington, D.C.: AOAC, 1995. 2000 p.

BOLSEN, K. K. Silage technology. In: AUSTRALIAN MAIZE CONFERENCE, 2., 1996, Queensland. Proceedings... Queensland: Gatton College, 1996. p. 1-30.

CABRAL, L. S.; VALADARES FILHO, S. C.; DETMANN, E.; ZERVOUDAKIS, J. T.; PEREIRA, O. G.; VELOSO, R. G.; PEREIRA, E. S. Cinética ruminal das frações de carboidratos, produção de gás, digestibilidade in vitro da matéria seca e NDT estimado da silagem de milho com diferentes proporções de grãos. Revista Brasileira de Zootecnia, Viçosa, MG, v. 31, n. 6, p. 2332-2339, 2002.

COMISSÃO DE QUÍMICA E FERTILIDADE DO SOLO - CQFS RS/SC. Manual de adubação e de calagem para os estados do Rio Grande do Sul e Santa Catarina. 10. ed. Porto Alegre: Sociedade Brasileira de Ciência do Solo/Núcleo Regional Sul, 2004. 400 p.
FILYA, I. Nutritive value and aerobic stability of whole crop maize silage harvested at four stages of maturity. Animal Feed Science Technology, Amsterdam, v. 116, n. 1-2, p. 141-150, 2004.

GOERING, H. K.; VAN SOEST, P. J. Forage fiber analysis: apparatus reagents, procedures and some applications. Washington, D. C.: Agricultural Handbook, 1970. $379 \mathrm{p}$.

HEINRICHS, P. J.; KONONOFF, P. J. Evaluating particle size of forages and TMRs using the new penn state forage particle separator. Pennsylvania: Pennsylvania State University, College of Agricultural Sciences, Cooperative Extension DAS 0242, 2002. 14 p.

HU, W.; SCHMIDT, R. J.; McDONELL, E. E.; KLINGERMAN, C. M.; KUNG JÚNIO, L. The effect of Lactobacillus buchneri 40788 or Lactobacilus plantarum MTD-1 on the fermentation and aerobic stability of corn silages ensiled at two dry matter contents. Journal of Dairy Science, Savoy, v. 92, n. 8, p. 3907-3914, 2009.

INSTITUTO AGRONÔMICO DO PARANÁ - IAPAR. Cartas climáticas do Paraná. Versão 1. 0. 2000. CD-ROM.

JOBIM, C. C.; NUSSIO, L. G.; REIS, R. A.; SCHMIDT, P. Avanços metodológicos na avaliação da qualidade de forragem conservada. Revista Brasileira de Zootecnia, Viçosa, MG, v. 36, p. 101-119, 2007. Suplemento Especial.

JOHNSON, L. M.; HARRISON, J. H.; DAVIDSON, D.; ROBUTTI, J. L.; SWIFT, M. Corn silage management I: Effects of hybrid, maturity and mechanical processing on chemical and physical characteristics. Journal of Dairy Science, Savoy, v. 86, n. 4, p. 833-853, 2002.

KONONOFF, P. J.; HEINRICH, A. J.; LEHMAN, H. A. The effect of corn silage particle size on eiting behavior, chewing actives and rumen fermentation in lactating dairy cows. Journal of Dairy Science, Savoy, v. 86, n. 10, p. 3343-3353, 2003.

MAACK, R. Geografia fisica do Estado do Paraná. 3. ed. Curitiba: Imprensa Oficial, 2002. 350 p.

MÜHLBACH, P. R. F. Silagem: produção com controle de perdas. In: LOBATO, J. F. P.; BARCELOS, J. O. J.; HESSLER, A. M. (Ed.). Produção de bovinos de corte. Porto Alegre: Pontifícia Universidade Católica, 1999. p. 97-120.

NEUMANN, M. Efeito do tamanho de partícula e da altura de colheita das plantas de milho (Zea mays L.) sobre perdas, valor nutritivo de silagens e desempenho de novilhos confinados. 2006. Tese (Doutorado em Zootecnia) - Curso de Pós-graduação em Zootecnia, Universidade Federal do Rio Grande do Sul, Porto Alegre. 
NEUMANN, M.; MÜHLBACH, P. R. F.; NÖRNBERG, J. L.; RESTLE, J.; OST, P. R. Efeito do tamanho de partícula e da altura de coheita das plantas de milho (Zea mays L.) sobre as perdas durante o processo fermentativo e o período de utilização das silagens. Revista Brasileira de Zootecnia, Viçosa, v. 36, n. 5, p. 1395-1405, 2007a.

NEUMANN, M.; MÜHLBACH, P. R. F.; RESTLE, J.; OST, P. R.; LUSTOSA, S. B. C.; FALBO, M. K. Ensilagem de milho (Zea mays L.) em diferentes alturas de corte e tamanho de partícula: Produção, composição e utilização na terminação de bovinos em confinamento. Revista Brasileira de Milho e Sorgo, Sete Lagoas, v. 6, n. 3, p. 379-397, 2007b.

NEUMANN, M.; OLIVEIRA, M. R.; ZANETTE, P. M.; UENO, R. K.; MARAFON, F.; SOUZA, M. P. Aplicação de procedimentos técnicos na ensilagem do milho visando maior desempenho animal. In: SIMPÓSIO SOBRE PRODUÇÃO E UTILIZAÇÃO DE FORRAGENS CONSERVADAS, 4., 2011, Maringá. Anais... Maringá: [s.n], 2011. p. 292.

NUSSIO, L. G.; MANZANO, R. P. Silagem de milho. In: SIMPÓSIO SOBRE NUTRIÇÃO DE BOVINOS: ALIMENTAÇÃO SUPLEMENTAR, 7., 1999, Piracicaba. Anais... Piracicaba: FEALQ, 1999. p. 27-46.

OBA, M.; ALLEN, M. S. Effects of brown mibrib 3 mutation in corn silage on productivity of dairy cows fed two concentrations of dietary neutral detergent fiber: 1. Feeding behavior an nutrient utilization. Journal of Dairy Science, Savoy, v. 83, n. 6, p. 1333-1341, 2000.

OLIVEIRA, M. R. Efeito do estádio de maturação na qualidade de silagens de milho na resposta econômica de novilhos confinados. 2010. Dissertação (Mestrado em Agronomia) - Curso de Pós-Graduação em Agronomia, Universidade Estadual do Centro Oeste, Guarapuava.

OLIVEIRA, M. R.; NEUMANN, M.; MENDES, M. C.; FARIA, M. V. F.; NERI, J. Resposta econômica na terminação de novilhos confinados com silagens de milho (Zea mays L.), em diferentes estádios de maturação, associadas a dois níveis de concentrado na dieta. Revista Brasileira de Milho e Sorgo, Sete Lagoas, v. 10, n. 2, p. 97-95, 2011.

POTT, C. A.; MÜLLER, M. M. L.; BERTELLI, P. B. Adubação verde como alternativa agroecológica para recuperação da fertilidade do solo. Revista Ambiência, Guarapuava, v. 3, n. 2, p. 51-63, 2007.

RABELO, C. H. S.; REZENDE, A. V.; NOGUEIRA, D. A.; RABELO, F. H. S.; SENEDESE, S. S.; VIEIRA, P. F.; BARBOSA, L. A.; CARVALHO, A. Perdas fermentativas e estabilidade aeróbica de silagens de milho inoculadas com bactérias ácido-láticas em diferentes estádios de maturidade. Revista Brasileira de Saúde Produção Animal, Salvador, v. 13, n. 3, p. 656-668, 2012.

RASBY, R. Understandig feed analysis. Lincoln: University of Nebraska-Lincoln, 2011. Available at: $<$ http://www.beef.unl.edu/learning/feedanalysis.shtml $>$. Accessed at: 30 maio 2012.

REIS, A. R.; JOBIM, C. C. Perfil da fração de carboidratos da planta e adequação deaditivos no processo de ensilagem. In: WORKSHOP SOBRE MILHO PARA SILAGEM, 2., 2000, Piracicaba. Anais ... Piracicaba: ESALQ, 2000. p. 27.

RESTLE, J.; NEUMANN, M.; BRONDANI, I. L.; PASCOAL, L. L.; SILVA, J. H. S.; PELLEGRINI, L. G.; SOUZA, A. N. M. Manipulação da altura de corte da planta de milho (Zea mays L.) para ensilagem visando a produção do novilho superprecoce. Revista Brasileira de Zootecnia, Viçosa, v. 31, n. 3, p. 1235-1244, 2002.

RITCHIE, S. W.; HANWAY, J. J.; BENSON, G. O. Como a planta de milho se desenvolve. Piracicaba: Potafos, 2003. 20 p. (Informações Agronômicas, 103).

SANTOS, E. M.; ZANINE, A. M.; FERREIRA, D. S. J.; OLIVEIRA, J. S.; PEREIRA, O. G.; ALMEIDA, J. C. C. Efeito da adição do soro de queijo sobre a composição bromatológica, fermentação, perdas e recuperação de matéria seca em silagem de capim-elefante. Ciência Animal Brasileira, Goiânia, v. 7, n. 3, p. 235-239, 2006.

STATISTICAL ANALYSIS SYSTEM INSTITUTE SAS INSTITUTE. SAS/STAT user's guide: statistics. 4. ed. Version 6. Cary, North Caroline, 1993. v. 2, 943 p.

SENGER, C. C. D.; MÜHLBACH, P. R. F.; BONNECARRÈRE SANCHEZ, L. M.; PERES NETTO, D.; LIMA, L. D. Composição e digestibilidade 'in vitro' de silagens de milho com distintos teores de umidade e níveis de compactação. Ciência Rural, Santa Maria, v. 35, n. 6, p. 1393-1399, 2005.

SILVA, D. J.; QUEIROZ, A. C. Análise de Alimentos, métodos químicos e biológicos. 3. ed. $4^{\mathrm{a}}$ reimp. Universidade Federal de Viçosa, 2009. 235 p.

SOUZA FILHO, A. X.; VON PINHO, R. G.; PEREIRA, J. L. A. R.; REIS, M. C.; REZENDE, A. V.; MATA, D. C. Influence of stage of maturity on bromatological quality of corn forage. Revista Brasileira de Zootecnia, Viçosa, MG, v. 40, n. 9, p. 1894-1901, 2011.

STOKES, M. R.; CHEN, J. Effect of an enzymeinoculant mixture on the course of fermentation od corn silage. Journal of Dairy Science, Savoy, v. 77, n. 11, p. 3401-3409, 1994. 
TABACCO, E.; RIGHI, F.; QUARANTELLI, A.; BORREANI, G. Dry matter and nutritional losses during aerobic deterioration of corn and sorghum silages as influenced by different lactic acid bacteria inocula. Journal of Dairy Science, Savoy, v. 94, n. 3, p. 14091419, 2011.

TOSI, H.; JOBIM, C. C. Conservação de forragens: silagem. In: AQUARONE, E.; BORZANI, W.; CHMIDELL, W.; LIMA, U. A. Biotecnologia industrial volume IV, biotecnologia na produção de alimentos. São Paulo: Editora Edgard Blücher Ltda, 2001. p. 491505.
VAN SOEST, P. J. Nutritional ecology of the ruminant. $2^{\text {th }}$ ed. Ithaca: Cornell University Press, 1994. $476 \mathrm{p}$.

VAN SOEST, P. J.; ROBERTTSON, J. B.; LEWIS, B. A. Methods for dietary fiber, neutral detergent fiber, and nonstarch polysaccharides in relation to animal nutrition. Journal of Dairy Science, Savoy, v. 74, n. 2, p. 35833597, 1991.

ZANETTE, P. M. Efeito da inclusão de açúcar ou inoculante bacteriano na silagem de milho sobre perdas, valor nutricional, desempenho e eficiência econômica de novilhos confinados. 2010. Dissertação (Mestrado em Agronomia) - Curso de Pós-Graduação em Agronomia, Universidade Estadual do Centro Oeste, Guarapuava. 
